\title{
APPLICATION OF ALPHA AND BETA BRAINWAVES ON E-LEARNING PROJECTS IN TERMS OF EXPANDING CRITICAL AND COGNITIVE SKILLS: AN EXPERIMENTAL APPROACH
}

\author{
Miltiadis Staboulis ${ }^{1}$ and Irene Lazaridou ${ }^{2}$ \\ ${ }^{1}$ Assistant Professor, Department of Educational and Social Policy, University of Macedonia, \\ 156 Egnatia str., GR-54636, Thessaloniki, Greece \\ ${ }^{2}$ Ph.D. Candidate, M.Ed.-M.Sc.-B.Sc.(Math), Department of Educational and Social Policy, University of Macedonia
}

\begin{abstract}
The present paper wishes to discuss some basic concepts of Brain-Based Learning and its relation to optimizing learning procedures through physical and on line educational practices. In particular it examines the combinational use of alpha and beta brain waves, embedded in teaching activities as a way of enhancing knowledge information flow, advancing cognitive and critical skills, while supporting a relaxing, calming, creative, actively thinking and problem solving environment in a balanced state of mind. The research that took place with 40 young adults has shown a strong positive correlation between alpha, beta waves and overall educational progress and skills enhancement.
\end{abstract}

\section{KEYWORDS}

ELearning, Skills, Education, Brain, Brainwaves, Educational Practices

\section{INTRODUCTION}

The numerous studies of the human brain have involved throughout the years, not only medical doctors but also other fields like education, psychology, pharmacology, mathematical modeling, molecular biology, anatomy, etc. finally creating the wide branch of neuroscience as the scientific study of the nervous system mainly in relation to behavior and learning. According to Eric Kandel (Nobel Prize 2000 for discoveries concerning signal transduction in the nervous system) the basics of learning, memory, behavior, perception and consciousness is the ultimate challenge of science. Due to its significance many sub branches have evolved like computational neuroscience (Schwartz, 1990) that mainly deals with neural modeling, brain theories and neural networks. Computational modeling of higher cognitive functions has recently begun, hoping to create the bases for modeling the brain's electrical activity (Robinson, et al, 2005). The results might be replicated in improving intelligent systems in the near future. In addition, the emerging field of neuroeducation is estimated to shape the learning practices, providing new opportunities for training and development professionals. Cognitive neuroscience is the study of mental brain processes and neural systems, including thinking and behavior, investigating biological ways involved in becoming literate, numerate in addition to exploring learning, cognitive control, flexibility and motivation together with social and emotional experiences (Dam, 2013).

Presently brain theories focus on a holistic view of the brain. Based on recent neurological research (Bonomo, 2017 \& Jensen, 2005) there are three relevant and essential features of the human brain: adaptability (the constantly changing brain), integration (the structures of the brain that compete and cooperate) and sophistication (the complexity of the brain).

The human brain is an amazing and complex living organ weighting about 1,1-1,4 kg that enables humans to talk, to think and to sense. A basic idea in its functionality is the fact that neurons' activity is both electrical and chemical. A neuron is a cell that communicates with other cells through synapses. A typical neuron consists of the cell body, the dendrites and the axon. The dendrites receive, the cell body integrates and the axon transmits and this is called polarization, because of the directional flow of information in the central nervous system as it is shown in Figure 1. The establishment and maintenance of neuronal polarization is crucial for correct development and function (Takano et al, 2015). 


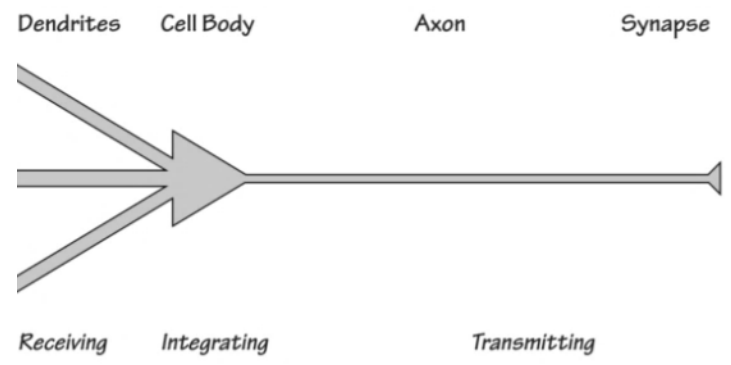

Figure 1. The basic concepts of a neuron

(Source: British Neuroscience Association)

These different parts of a neuron are in constant motion. The dendrites can change shape, sprout new connections or even withdraw from others and the axons grow new endings as the neuron struggles to communicate with other neurons. So, a neuron is like a miniature calculator constantly adding and subtracting messages from other neurons. These signals constitute the basis of sensation, thought and movement depending on the network the neurons are embedded (British Neuroscience Association, 2019). This dynamic and flexible ability of the brain leads to the fact that the brain is shaped by experiences and proper environmental enrichment, as the axonal circuits change, modify and redevelop even in older ages, providing an amazing plasticity throughout life (Jensen, 2000). So the brain changes as a result of experience and this happens much quicker than originally thought. The environment in which the brain operates determines, to a large degree, the functional ability of the brain (Roberts, 2002). As a result, learning is a physical process in which new knowledge is represented by new brain cell connections. The strength and formation of these connections are facilitated by chemicals in the brain called growth factors. Thus the creation of neural networks and synapses are what constitutes learning (Fishback, 1999). Consequently the term brain-based learning has evolved, studying the design of enriching appropriate experiences for learners while ensuring ways to increase the extraction of meaning of the received knowledge (Caine \& Caine, 1991). Due to brain's neuroplasticity, some general ideas are now widely accepted, such as the brain is able to perform several tasks at once, the same information can be stored in multiple areas of the brain and learning functions can be affected by several reasons (exercise, diet, stress, emotional state, etc.).

As a result, schools, teachers, educators and educational programs have been recently trying to create certain conditions that facilitate learning activities. It is obvious that if some certain new model or way appears that significantly helps in advancing common learning procedures, then a whole new educational era could be on the way Yet as educational neuroscience is a relatively new field, the methods, strategies and development of cognitive science are still under progress, debate and testing.

Due to the fact that the brain is an electrochemical organ, the synchronized electrical pulses from neurons communicating with each other produce brain waves. Hans Berger (1873-1941), a German psychiatrist invented electroencephalography (EEG) for the recording of brain waves in 1924, by measuring electrical activity in the brains of hospital patients with skull damage. He documented alpha waves along with beta waves activity. He found out that when alpha waves decrease and beta activity becomes dominant, a person is fully awake. Today brainwaves are detected by using sensors placed on the scalp. One may think of brainwaves as musical notes of different frequencies that are able to change according to what we do or feel. Brainwaves accompany many mental stages and they occur in different locations of the brain. In fact, nowadays, many mobile applications offer real time feedback on brain activity in order to promote relaxation, alertness, mindfulness, etc. They work as EEG devices that passively sense brain's activity, promoting human centered technology.

Brainwaves are measured in Hertz (cycles per second) and they can be slow, moderate or fast, according to certain activities as shown in Figure 2. 


\begin{tabular}{l|l|l} 
Brain Waves & Brain State & Frequency $(\mathbf{H z})$ \\
\hline Delta & Sleep & $1-3$ \\
\hline Theta & Alert & $4-7$ \\
\hline Low Alpha & Relaxed & $8-9$ \\
\hline High Alpha & Relaxed & $10-12$ \\
\hline Low Beta & Focused & $13-17$ \\
\hline High Beta & Focused & $18-30$ \\
\hline Low Gamma & Multi-Processing & $31-40$ \\
\hline High Gamma & Multi-Processing & $41-50$
\end{tabular}

Figure 2. The brainwaves, states and frequencies

(Source: https://www.researchgate.net/figure/List-of-brainwaves-with-state-and-their-frequencies_tbl1_305681552)

At the moment brainwaves are already connected to areas such as self-development, emotional balance, stress and anxiety, sleep and fatigue and are even connected to more specific issues such as trauma, PTSD, autism, dyslexia, etc.(https://brainworksneurotherapy.com). According to Jacobs (2018), waves are widespread in the human cortex (the part of the brain of higher cognitive functions) and they become more organized depending on how well the brain is performing a task. As a result, more consistent waves correspond to better task performance. These findings appear to support the concept that brainwaves are relevant to behavior, contributing to memory, perception, attention and even consciousness (Makin, 2018).

Based on the above facts, the present paper examines the consecutive use of alpha and beta waves by incorporating these waves in common traditional and on line teaching procedures, examining any possible progress in knowledge information flow, metacognition, expansion of cognitive and critical skills and thus optimization in the overall learning procedures, under certain predefined criteria. The reason of the combinational use of alpha and beta waves relies to the fact that alpha waves initially promote a calm, relaxing and creative state of mind while beta waves promote an engaged, alert and well-focused mind.

\section{RESEARCH}

The present research involves a sample of $\mathrm{N}=40$ young adult math graduates (23-28 years old, both male (24) and female (16)), with the intention of becoming intermediate level math teachers. Their university degree mark ranged from 5-6.2 (top mark is 10) so their overall performance as math students might be considered average. For this reason they choose a three month self-financing educational program of 300 hours about recent math teaching methods and techniques and latest mathematical software for calculations and graphical representations. According to the program's structure they joined a blended course that provided 100 hours of traditional teaching and 200 hours of on line learning

During the first meeting, they were notified about the contents of the program, the goals and the ways of evaluation and were asked for permission in using a combination of brain waves during the lessons as part of an experimental possible enhancement in learning procedures. They all agreed and gave in their written permission. Afterwards the sample was randomly divided into two equal groups of 20 namely group A $(\mathrm{A} 1, \ldots, \mathrm{A} 20)$ and group B (B1,..,B20). From that day on, group A (receivers) was always in contact with alpha and beta brain waves (both in physical teaching and with embedded sounds during on line learning), while group B (non receivers) received none. The combination of brain waves used ranged from 10-15 minutes of alpha waves (in order to relax and calm the brain) and 30-35 minutes of beta waves (in order to promote active thinking and problem solving skills).

In addition to the use of these waves, the educational material was structured in detail with very clear and segmented goals, so as to establish easy and accurate evaluation criteria during each month of the course. The evaluation criteria, during each month of the course, were divided into 3 parts (written evaluation, oral presentations and teaching simulations) as a repeated procedure at the end of every month. The marking scale was set from 1-10 (10 being the top mark). From the three different evaluations for every student, the average was calculated and kept for further comparisons. As this average mark for every single student, derives from a triple way of evaluation, it might be safe to conclude that it is an accurate and representative mark for each and every one of them. Obviously, each mark was entered in an Access data base for further processing. The first month appeared to be a period of adaptation that rapidly changed during the following two months. During the first month they became adapted to the requirements of the program while the evaluations at the end of the $1^{\text {st }}$ month, appeared to be pretty similar (group A held an average mark of 5.8 while group B received 5.9). If the particular research had stopped at the end of the first month, no one could have guessed the upcoming changes. At the end of $2^{\text {nd }}$ month, the average evaluation mark shows in tables 1 and 2 for both groups precisely. 
Table 1. Evaluation in Group A (receivers)

\begin{tabular}{|c|c|c|c|c|c|c|c|c|c|c|c|c|c|c|c|c|c|c|c|}
\hline \multicolumn{20}{|c|}{ (Group A) Evaluation at the end of the $2^{\text {nd }}$ month } \\
\hline $\mathrm{A} 1$ & $\frac{1}{A} 2$ & A3 & $\mathrm{A} 4$ & A5 & A6 & A7 & $\mathrm{A} 8$ & A9 & $\mathrm{A} 10$ & A11 & $\mathrm{A} 12$ & $\mathrm{~A} 13$ & $\mathrm{~A} 14$ & A15 & A16 & A17 & $\mathrm{A} 18$ & $\mathrm{~A} 19$ & $\mathrm{~A} 20$ \\
\hline 7 & 7 & 8 & 9 & 6 & 7 & 6 & 7 & 7 & 9 & 9 & 8 & 7 & 7 & 9 & 8 & 6 & 8 & 7 & 8 \\
\hline
\end{tabular}

The average performance of group A (receivers) at the end of the $2^{\text {nd }}$ month was $\mathrm{X}_{\mathrm{A}(2)}=7.5$

Table 2. Evaluation in Group B (non receivers)

\begin{tabular}{|c|c|c|c|c|c|c|c|c|c|c|c|c|c|c|c|c|c|c|c|}
\hline \multicolumn{20}{|c|}{ (Group B) Evaluation at the end of the $2^{\text {nd }}$ month } \\
\hline B1 & B2 & B3 & B4 & B5 & B6 & B7 & B8 & B9 & $\mathrm{B} 10$ & B11 & B12 & $\mathrm{B} 13$ & B14 & B15 & B16 & B17 & $\mathrm{B} 18$ & B19 & B20 \\
\hline 7 & 7 & 6 & 6 & 6 & 5 & 6 & 6 & 5 & 7 & 7 & 6 & 7 & 5 & 5 & 7 & 7 & 8 & 8 & 9 \\
\hline
\end{tabular}

The average performance of group $\mathrm{B}$ (non receivers) at the end of the $2^{\text {nd }}$ month was $\mathrm{X}_{\mathrm{B}(2)}=6.5$ Similarly, at the end of $3^{\text {nd }}$ month, the average evaluation appears in tables 3 and 4.

Table 3. Evaluation in Group A (receivers)

\begin{tabular}{|c|c|c|c|c|c|c|c|c|c|c|c|c|c|c|c|c|c|c|c|}
\hline \multicolumn{10}{|c|}{ (Group A) Evaluation at the end of the $3^{\text {nd }}$ month } & & & & & & & & & & \\
\hline $\mathrm{A} 1$ & $\mathrm{~A} 2$ & $\mathrm{~A} 3$ & $\mathrm{~A} 4$ & A5 & $\mathrm{A} 6$ & A7 & A8 & A9 & A10 & A11 & A12 & A13 & $\mathrm{A} 14$ & $\mathrm{~A} 15$ & A16 & A17 & $\mathrm{A} 18$ & A19 & A20 \\
\hline 9 & 8 & 9 & 9 & 7 & 8 & 8 & 7 & 8 & 9 & 9 & 8 & 8 & 8 & 9 & 8 & 7 & 8 & 8 & 9 \\
\hline
\end{tabular}

The average performance of group $\mathrm{A}$ (receivers) at the end of the $3^{\text {nd }}$ month was $\mathrm{X}_{\mathrm{A}(3)}=8.2$

Table 4. Evaluation in Group B (non receivers)

\begin{tabular}{|c|c|c|c|c|c|c|c|c|c|c|c|c|c|c|c|c|c|c|c|}
\hline \multicolumn{20}{|c|}{ (Group B) Evaluation at the end of the $3^{\text {nd }}$ month } \\
\hline B1 & B2 & B3 & B4 & B5 & B6 & B7 & B8 & B9 & B10 & B11 & B12 & $\mathrm{B} 13$ & B14 & B15 & B16 & B17 & $\overline{\mathrm{B} 18}$ & B19 & $\bar{B} 20$ \\
\hline 7 & 7 & 6 & 7 & 6 & 6 & 6 & 7 & 6 & 7 & 7 & 6 & 7 & 6 & 5 & 8 & 7 & 8 & 8 & 9 \\
\hline
\end{tabular}

The average performance of group $\mathrm{B}$ (non receivers) at the end of the $3^{\text {nd }}$ month was $\mathrm{X}_{\mathrm{B}(3)}=6.8$

From the above, it derives that the course in general had an overall positive effect on every participant as there is a clear rising. Obviously the group A (receivers) holds an amazing overall improvement starting with the average of 5.8 and reaching 8.2 out of 10 . Figure 3, below, shows the comparison between the evaluation average marks among the two groups, throughout the entire three month program.

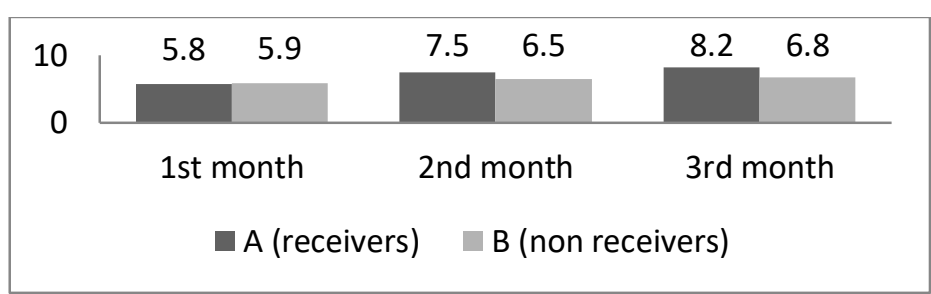

Figure 3. Comparison of evaluation average mark in both groups A and B during the entire 3-month course

The statistical analysis (t-test) of the results of the $3^{\text {rd }}$ month for both groups A and B, show the following:

- P value and statistical significance: The two-tailed $\mathrm{P}$ value is less than 0.0001. By conventional criteria, this difference is considered to be extremely statistically significant.

- Confidence interval: The mean of Group A minus Group B equals 1.40. 95\% confidence interval of this difference: From 0.87 to 1.93 .

- Intermediate values used in calculations: $\mathrm{t}=5,3115, \mathrm{df}=38$, standard error of difference $=0.264$.

There are many questions unanswered, like why there was no rising during the first month, what would be the progress of group A if the program held longer, what would happen with group B performance given more time while turning them into receivers, what elements enriched group A self-motivation during the $2^{\text {nd }}$ and $3^{\text {rd }}$ month, was the quality of the educational material of the same significance with the use of brain waves, what other parameters hold a basic role, would the results be the same if we repeat the research using another sample of bigger scale and may another educational program, can we assume or prove that if repeated it would lead to the same results, etc. Of course, despite the fact that there is an obvious positive correlation between alpha, 
beta brainwaves and learning enhancement in the present research, there are still many restrictions such as the relatively small sample of 40 participants and the short period of the research itself. Another limitation could be related to the nature of the sample as it is formed from young average smart adults hoping for a better working position, knowing that to achieve this, they must do their best. So it might be said that the particular sample was already in the appropriate mood for effective learning.

\section{CONCLUSION}

From the above it derives that learning mechanisms are closely related to the brain's general state and that the calculated combination of alpha and beta brainwaves appears to have a positive role in overall learning optimizations. It also seems that alpha and beta waves may hold a significant part in eLearning courses where usually self motivation, responsibility and independence are in great demand compared to traditional courses, simply because the common student to teacher interaction is relatively limited. In the present research, the outcomes seem pretty astonishing and further investigation is needed in order to bring more light into the matter. As effective learning always involve alternation of several states of arousal (Caine \& Caine, 1991), it appears that the alpha and beta waves contribute to this idea, possibly by helping the human brain to stay interconnected, calm, alert and focused. It is well known that emotions are critical to patterning and patterning is one of the ways that human brain learns. If the outcomes of this research are further verified, the results could open a whole new door to new learning theories, practices, strategies and curriculum programs. They could be applied in vocational education and training programs as well as in all levels of typical education and even in business environments using effective strategies, empowering reflection and metacognition progresses in order to finally create persons and citizens with deeper knowledge and enriched skills that could be used to achieve a happier and more fulfilled daily life.

\section{ACKNOWLEDGEMENT}

We would like to thank Dr.Taskos Nikolaos, Professor of Neurology, Department of Medicine (Aristotle University of Thessaloniki, Greece) for his useful collaboration to the present paper and the research itself.

\section{REFERENCES}

Bonomo V., 2017. Brain-Based Learning Theory. Journal of Education and Human Development, Vol.6, No.1, pp 27-43. British Neuroscience Association (BNA), 2019. Neuroscience: Science of the brain-An introduction for young students. Liverpool, BNA.

Caine, G., Nummela-Caine, R. (1991). Making Connections: Teaching and the Human Brain. Menlo Park, CA.: Addison-Wesley Longman, Incorporated.

Dam N., 2013. Inside the learning brain. Association for talent development. www.td.org (30-03-2019)

Fishback, S. J., (1999). Learning and the brain. Adult learning, 10 (2), pp 18-23.

Jensen, E., 2005. Teaching with the brain in mind. Alexandria, VA: ASCD.

Jensen, E., 2000. Brain based learning. San Diego, CA: The Brain Store.

Makin, S., 2018. Travelling brainwaves maybe critical for cognition. Scientific American, https://www.scientificamerican.com/article/traveling-brain-waves-may-be-critical-for-cognition/

Robinson PA. et al, 2005. Multiscale brain modeling. Philosophical Transactions of the Royal Society B. 360 (1457), pp 1043-1050.

Roberts, J. W., 2002. Beyond learning by doing: The brain compatible approach. The Journal of Experiential Education. 25 (2), pp 281-285.

Schwartz, E., 1990. Computational neuroscience. Cambridge, Mass: MIT Press.

Takano T. et al, 2015. Neuronal polarization. National Center of Biotechnology Information (NCBI). 142 (12), pp 2088-93. 